\title{
Trends in overweight and obesity in pre-school children in urban areas of Ho Chi Minh City, Vietnam, from 2002 to 2005
}

\author{
Huynh Thi Thu Dieu ${ }^{1, *}$, Michael J Dibley ${ }^{2}$, David W Sibbritt ${ }^{3}$ and Tran Thi Minh Hanh ${ }^{1}$ \\ ${ }^{1}$ Nutrition Centre of Ho Chi Minh City, 180 Le Van Sy, Phu Nhuan District, Ho Chi Minh City, Vietnam: ${ }^{2}$ School \\ of Public Health and The George Institute for International Health, University of Sydney, Sydney, Australia: \\ ${ }^{3}$ Centre for Clinical Epidemiology and Biostatistics, Faculty of Health, University of Newcastle, Newcastle, \\ Australia
}

Submitted 31 0ctober 2007: Accepted 2 May 2008: First published online 29 July 2008

\begin{abstract}
Objective: To assess the trends in overweight and obesity in pre-school children in urban areas of Ho Chi Minh City (HCMC), Vietnam, over the period 2002 to 2005. Design: Two cross-sectional studies were conducted in 2002 and 2005. Multistage cluster sampling was used in both surveys to select the subjects. Sociodemographic information was collected using a self-administered questionnaire given to parents in 2002 and using an interview-administered questionnaire to parents in 2005. Weight and height were measured using the same standard methods in both surveys. BMI $\left(\mathrm{kg} / \mathrm{m}^{2}\right)$ was calculated and overweight/obesity was defined using the age- and sex-specific BMI cut-off points proposed by the International Obesity Taskforce.

Subjects and setting: Children aged 4 to 5 years, attending pre-schools in urban areas of HCMC, Vietnam, in 2002 ( $n$ 492) and 2005 ( $n$ 670).

Results: The prevalence of overweight and obesity almost doubled from 2002 to 2005 (21.4\% and 36.8\%, respectively). The increase was more evident in less wealthy districts than in wealthy districts. The proportion of boys classified as obese in $2005(22.5 \%)$ was three times that in 2002 (6.9\%).

Conclusion: The prevalence of overweight and obesity has increased rapidly in children aged 4 to 5 years in urban areas, and especially in less wealthy districts, over a 3-year period. These results signal an urgent need for prevention programmes to control and reverse this rapid upward trend in overweight and obesity in young children in HCMC.
\end{abstract}

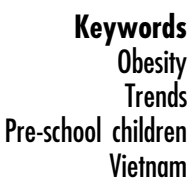

The shift towards overweight and obesity compared with underweight taking place in the developing world today has been suggested to be faster than that observed earlier in developed countries such as the USA or Europe ${ }^{(1,2)}$. Rapid socio-economic development and urbanization are important determinants for the current changes in disease patterns in the developing world, where infectious diseases and malnutrition are decreasing and overnutrition and its complications are increasing ${ }^{(1-3)}$.

The economic situation in Vietnam has improved considerably during the past two decades, especially in Ho Chi Minh City (HCMC), which is an economic and trade centre for southern Vietnam and has the highest rate of economic development in the country ${ }^{(4)}$. The effects of rapid economic development on the nutritional status of the child population in HCMC are similar to those seen in other developing countries undergoing a 'nutrition transition $^{(5,6)}$. An increasing prevalence of overweight and obesity has been documented in adolescents in urban districts of HCMC over a period of 2 years from $5.6 \%$ in 2002 to $13 \cdot 7 \%$ in $2004^{(5)}$. Meanwhile, the prevalence of underweight has decreased significantly in the same population $(13 \cdot 1 \% \text { in } 2002 \text { to } 6 \cdot 7 \% \text { in } 2004)^{(5)}$. This epidemic appears to be more advanced in pre-school children where the level of overweight and obesity according to the International Obesity Taskforce (IOTF) definition in urban areas of HCMC in 2005 was $36 \cdot 8 \%^{(6)}$, comparable to or even higher than that reported recently in children of similar age in developed countries such as Canada in 2002 $(36 \cdot 0 \%)^{(7)}$ and the USA in $2004(26 \cdot 2 \%)^{(8)}$. However, the speed at which overweight and obesity has emerged in this young child population in urban areas of HCMC has not been examined. The present paper aims to assess trends in the prevalence of overweight and obesity among children aged 4 to 5 years in pre-schools in urban areas of HCMC over the period 2002 to 2005. 


\section{Subjects and methods}

\section{Population and study design}

The trends in overweight and obesity were examined using data from cross-sectional studies of children aged 4 to 5 years in pre-schools in HCMC in 2002 and 2005. In both the 2002 and 2005 surveys, a multistage cluster sampling strategy was used to select children. The 2002 study aimed to investigate the prevalence of overweight in children attending pre-schools throughout HCMC. Sixty schools were selected across all of HCMC using a proportionate to school population size method (PPS) in the first stage. Systematic random sampling was used to recruit thirty children aged 1 to 6 years based on a sampling frame of all children in each selected school. Overall, 1792 children aged 1 to 6 years and their parents, in the sixty selected schools, completed the study measurements with 1168 children from urban and 628 children from suburban areas. In the analyses presented in the current paper, the sample was limited to children aged 4 to 5 years living in the urban areas only, in order to ensure a valid comparison of the prevalence of overweight and obesity in children of the same age in 2002 and 2005. This restriction reduced the sample to 492 children aged 4 to 5 years in thirty-nine preschools in urban areas of HCMC.

The survey in 2005, which was a baseline measurement for a one-year follow-up study ${ }^{(6)}$, used two-stage cluster sampling with stratification by groups of districts (wealthy and less wealthy districts) in the first stage. Twenty pre-schools were selected in the first stage using a PPS method based on a frame of all pre-schools in urban areas of HCMC. In the second stage, thirty-five children aged 4 to 5 years were recruited from a prepared list of all children of similar age in each selected school using systematic random sampling. There were 670 children aged 4 to 5 years, and their parents, participating in this study.

The ethical approval for both studies was obtained from the Health Service of HCMC. The trend analyses using the 2002 survey data, and procedures used in the 2005 study, were also approved by the Human Research Ethics Committee of the University of Newcastle, Australia.

\section{Measurements and data collection}

In both surveys, weight and height were measured using the same standard methods. Anthropometry was collected by physicians from the Nutrition Centre of HCMC who, before data collection began, had their measurement methods standardized as described in an anthropometric standardization reference manual ${ }^{(9)}$. Weight was measured with shoes and jackets removed, using Tanita electronic scales (Tanita BF 571, Japan) and recorded to nearest $0 \cdot 1 \mathrm{~kg}$. Height was measured with shoes and hats removed, using a Microtoise tape suspended from a wall and recorded to the nearest $0 \cdot 1 \mathrm{~cm}$.
In the 2002 survey, information on sociodemographic factors, the child's birth history and eating habits were collected using a self-administered questionnaire at least one week prior to the survey taking place at the preschools. Information collected included the highest education level of parents, parental reported weight and height, whether the child was breast-fed, and the frequency of consumption of fast foods, soft drinks, sweets, ice cream, fruit and vegetables.

In the 2005 survey, information on sociodemographic factors was collected from the parents or the main caregiver using pre-coded, structured, interview-administered questionnaires. The information collected included parental ethnicity, occupation, education, self-reported parental weight and height, and ownership of seventeen household assets including household vehicles, entertainment appliances and household appliances. The birth history characteristics of the children were captured including the child's birth weight and duration of breastfeeding; and the average current amount of time per night for the child to sleep was also collected. The child's birth weight in both surveys was based on parental report of the weight measurement taken in the hospital of birth.

\section{Data management and statistical analysis}

Data in both surveys were entered on computer using the Epi Info ${ }^{\mathrm{TM}}$ program version 6 (Centers for Disease Control and Prevention (CDC), Atlanta, GA, USA) using standardized procedures and data-checking files. All data were examined for missing values and outliers and cleaned by re-checking with the questionnaire prior to data analysis.

BMI $\left(\mathrm{kg} / \mathrm{m}^{2}\right)$ in children was calculated. The age- and gender-specific BMI cut-off points recommended by the IOTF $^{(10)}$ were used to define overweight and obesity among children aged 4 to 5 years in the two studies. The weight-for-age $Z$ scores, height-for-age $Z$ scores and BMIfor-age $Z$ scores were calculated based on the 2000 CDC Growth Reference ${ }^{(11)}$. The 5 th percentile was the cut-off point used to classify underweight, stunting and wasting in this child population.

The overweight status of parents in both studies was assessed based on the BMI calculated from self-reported weight and height, using the cut-off point of $23 \mathrm{~kg} / \mathrm{m}^{2}$ recommended for Asian populations ${ }^{(12)}$.

In both surveys the urban districts were categorized into wealthy areas (four urban districts) and less wealthy areas (eight urban districts) using the same economic status classification method from the Statistical Office of $\mathrm{HCMC}^{(4)}$.

SVYSET commands in the STATA statistical software package version $9 \cdot 0$ (StataCorp LP, College Station, TX, USA), which use Taylor linearized variance estimation, adjusted the analyses for the cluster sampling design in both studies. The estimates for each study were weighted based on the child population in the pre-schools from wealthy $v$. less wealthy urban areas. 
The distribution of weight, height and BMI is described by mean and standard deviation according to demographic group for each study. The prevalence of overweight, obesity and underweight together with 95\% confidence intervals is calculated across sociodemographic groups. Categorical data comparisons were tested with Pearson $\chi^{2}$ tests, while normally distributed continuous data were tested with Student's $t$ tests. To test for trends in the prevalence of overweight and obesity from 2002 to 2005, logistic regression analysis was used with year of survey as predictor in the models adjusting for age, gender, parental overweight status and parental education level.

In addition, the frequency of children in 0.5 BMI-forage $Z$-score intervals from the CDC 2000 Growth Reference was plotted and smoothed with a Lowes function to construct BMI-for-age $Z$-score frequency distribution curves to assess changes in the BMI-for-age $Z$-score distributions between the two studies ${ }^{(13)}$.

Comparability of the methods used in the two surveys is presented in Table 1.

\section{Results}

Overall, there were 492 children aged 4 to 5 years in the 2002 survey, with the proportion of boys about $10 \%$ higher than that of girls $(55 \cdot 9 \%$ and $44 \cdot 1 \%$, respectively). The gender distribution of the 670 children participating in the 2005 study was approximately equal ( $49 \cdot 7 \%$ boys and $50 \cdot 3 \%$ girls).

The characteristics of children including age, gender, birth weight, weight, height, BMI and parental BMI in the two surveys are presented in Table 2 . In general, children of both genders in the 2002 survey were approximately 1.0 to 1.5 months older than the children in the 2005 survey $(P<0 \cdot 001)$. However, children of both genders in 2005 were heavier at birth than children in the 2002 survey $(P=0 \cdot 001)$. Also, the mean weight of children of both genders increased significantly from 2002 to 2005 $(P<0.001)$ while their mean height did not change significantly $(P=0 \cdot 249$ for boys and $P=0 \cdot 123$ for girls $)$. Thus, the mean BMI of children of both genders changed significantly over the 3 -year period $(P<0 \cdot 001)$. There was no significant difference in mean parental BMI for boys $(P=0 \cdot 502)$ or girls $(P=0 \cdot 430)$.

Figure 1 shows that the BMI-for-age $Z$-score distribution for all children in 2005 was shifted further to the right than that for all children in 2002, and indicates that the BMI distribution in 2005 was higher than in 2002. In addition, the BMI-for-age $Z$-score distribution curve for children in the 2005 survey was above the CDC reference curve, indicating a higher BMI in this child population in HCMC than for children in the reference population.

Figure 2 plots the frequency distribution of BMI-for-age $Z$ score for children from wealthy districts in the 2002 and 2005 surveys. There was a small difference in the distribution of BMI-for-age $Z$-score curves on the righthand side between the two time points. However, the lefthand side of the distribution curve for children in 2005 was shifted further to the right than that for children in 2002. These changes combined indicate that undernutrition decreased and overnutrition increased slightly for children from wealthy districts in 2005 compared with 2002.

Table 1 Comparison of methods used in two surveys to assess trends in overweight and obesity in pre-school children from urban areas of Ho Chi Minh City (HCMC), Vietnam

\begin{tabular}{|c|c|c|}
\hline Method & $2002^{*}$ & 2005 \\
\hline Target population & $\begin{array}{l}\text { Children aged } 4 \text { to } 5 \text { years who were enrolled in } \\
\text { pre-schools in the urban population of HCMC } \\
\text { province }\end{array}$ & $\begin{array}{l}\text { Children aged } 4 \text { to } 5 \text { years who were enrolled in pre- } \\
\text { schools in the urban population of HCMC province }\end{array}$ \\
\hline Study design & Cross-sectional study & Cross-sectional study \\
\hline Sampling & $\begin{array}{l}\text { Two-stage cluster sampling with PPS method to } \\
\text { select pre-schools } \\
\text { Use of systematic random sampling to sample } \\
\text { the children }\end{array}$ & $\begin{array}{l}\text { Two-stage cluster sampling with stratification by group } \\
\text { of districts at the first stage and PPS method to select } \\
\text { pre-schools } \\
\text { Use of systematic random sampling to sample the children }\end{array}$ \\
\hline Measurements & $\begin{array}{l}\text { Weight and height were measured using standard } \\
\text { methods by staff of the Nutrition Centre of HCMC } \\
\text { Information on sociodemographic factors, the } \\
\text { child's birth history and eating habits were } \\
\text { collected using a self-administered questionnaire } \\
\text { to parents or main caregiver }\end{array}$ & $\begin{array}{l}\text { Weight and height were measured using standard } \\
\text { methods by staff of the Nutrition Centre of HCMC } \\
\text { Information on sociodemographic factors was collected } \\
\text { from the parents or the main caregiver using pre-coded, } \\
\text { structured interview-administered questionnaires by } \\
\text { staff of the Nutrition Centre of HCMC }\end{array}$ \\
\hline Analysis & $\begin{array}{l}\text { IOTF definition was used to classify overweight } \\
\text { and obesity } \\
\text { The wealth of districts was defined based on } \\
\text { classification from the Statistical Office of HCMC }\end{array}$ & $\begin{array}{l}\text { IOTF definition was used to classify overweight } \\
\text { and obesity } \\
\text { The wealth of districts was defined based on classification } \\
\text { from the Statistical Office of HCMC; no change in status } \\
\text { of any districts compared with } 2002 \text { survey } \\
\text { Use of sampling weights to adjust for the stratified } \\
\text { sampling and ensure comparability with the } 2002 \text { survey }\end{array}$ \\
\hline
\end{tabular}

PPS, proportionate to school population size method; IOTF, International Obesity Taskforce.

${ }^{*}$ Restricted sample with children aged 4 to 5 years in urban areas. 
Table 2 Characteristics of children aged 4 to 5 years by gender in the 2002 and 2005 surveys, urban areas of Ho Chi Minh City, Vietnam

\begin{tabular}{|c|c|c|c|c|c|}
\hline \multirow[b]{2}{*}{ Characteristic } & \multicolumn{2}{|c|}{2002 survey ( $n$ 492) } & \multicolumn{2}{|c|}{2005 survey $(n 670)$} & \multirow[b]{2}{*}{$P^{*}$} \\
\hline & Mean & $95 \% \mathrm{Cl}$ & Mean & $95 \% \mathrm{Cl}$ & \\
\hline \multicolumn{6}{|l|}{ Boys } \\
\hline Birth weight $(\mathrm{g})$ & $3126 \cdot 7$ & $3070 \cdot 1,3183 \cdot 3$ & $3197 \cdot 9$ & $3147 \cdot 0,3248 \cdot 8$ & 0.0317 \\
\hline Weight $(\mathrm{kg})$ & $18 \cdot 7$ & $18 \cdot 1,19 \cdot 3$ & $20 \cdot 1$ & $19 \cdot 5,20 \cdot 7$ & 0.0000 \\
\hline Height $(\mathrm{cm})$ & $107 \cdot 2$ & $106 \cdot 3,108 \cdot 0$ & $107 \cdot 6$ & $106 \cdot 9,108 \cdot 2$ & $0 \cdot 2495$ \\
\hline BMI $\left(\mathrm{kg} / \mathrm{m}^{2}\right)$ & $16 \cdot 2$ & $15 \cdot 9,16 \cdot 5$ & $17 \cdot 2$ & $16 \cdot 9,17 \cdot 6$ & 0.0000 \\
\hline Paternal BMI $\left(\mathrm{kg} / \mathrm{m}^{2}\right)$ & $22 \cdot 4$ & $22 \cdot 1,22 \cdot 8$ & $22 \cdot 2$ & $21 \cdot 8,22 \cdot 6$ & 0.5018 \\
\hline Maternal BMI $\left(\mathrm{kg} / \mathrm{m}^{2}\right)$ & $21 \cdot 0$ & $20 \cdot 6,21 \cdot 4$ & $21 \cdot 0$ & $20 \cdot 6,21 \cdot 3$ & 0.9198 \\
\hline \multicolumn{6}{|l|}{ Girls } \\
\hline Birth weight $(\mathrm{g})$ & $3042 \cdot 2$ & $2998 \cdot 0,3086 \cdot 5$ & $3118 \cdot 4$ & $3067 \cdot 8,3169 \cdot 1$ & 0.0289 \\
\hline Weight $(\mathrm{kg})$ & $17 \cdot 7$ & $17 \cdot 3,18 \cdot 1$ & $18 \cdot 9$ & $18 \cdot 3,19 \cdot 5$ & 0.0000 \\
\hline Height $(\mathrm{cm})$ & $106 \cdot 1$ & $105 \cdot 5,106 \cdot 8$ & $106 \cdot 6$ & $105 \cdot 9,107 \cdot 3$ & $0 \cdot 1235$ \\
\hline $\mathrm{BMI}\left(\mathrm{kg} / \mathrm{m}^{2}\right)$ & $15 \cdot 6$ & $15 \cdot 3,15 \cdot 9$ & $16 \cdot 6$ & $16 \cdot 2,16 \cdot 9$ & 0.0000 \\
\hline Paternal BMI $\left(\mathrm{kg} / \mathrm{m}^{2}\right)$ & $22 \cdot 4$ & $22 \cdot 0,22 \cdot 7$ & 22.5 & $22 \cdot 2,22 \cdot 8$ & 0.4305 \\
\hline Maternal BMI $\left(\mathrm{kg} / \mathrm{m}^{2}\right)$ & $20 \cdot 7$ & $20 \cdot 5,21 \cdot 0$ & $21 \cdot 1$ & $20 \cdot 8,21 \cdot 5$ & 0.0699 \\
\hline
\end{tabular}

${ }^{*} P$ value was calculated from Student's $t$ test.

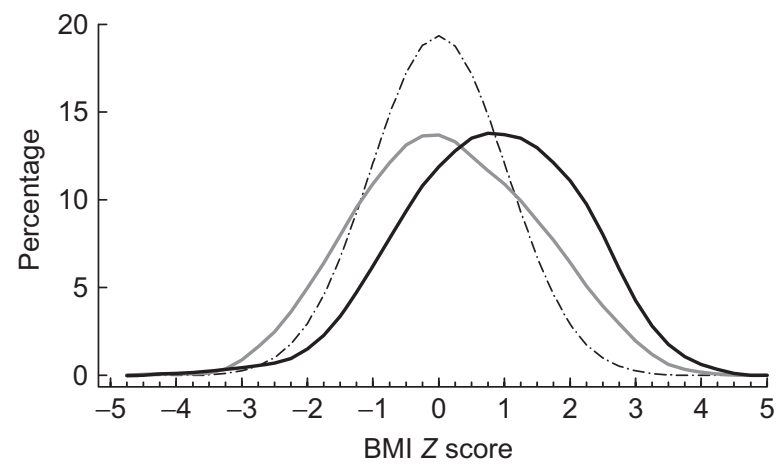

Fig. 1 Plot (Lowes curves) of BMI-for-age Z-score distributions for children aged 4 to 5 years from urban areas of Ho Chi Minh City, Vietnam, according to the 2002 (-) and 2005 surveys (-) and comparison with reference BMI curve (--.) based on the Centers for Disease Control and Prevention 2000 Growth Reference ${ }^{(11)}$

The entire BMI-for-age $Z$-score distribution for children from less wealthy districts in 2005 was skewed to the right compared with that for children in 2002 (Fig. 3). Thus, the BMI of children from less wealthy areas in 2005 was higher than that in 2002. Also, a greater shift towards higher values (shifted to the right) of the BMI-for-age $Z$-score distribution took place in children from less wealthy districts compared with children from wealthy areas.

The changes in patterns of underweight, overweight and obesity of children by gender and group of districts in the two surveys are presented in Table 3. In general, the prevalence of underweight in both genders decreased significantly over the 3 -year period $(P<0 \cdot 001)$. This decrease in the prevalence of underweight was statistically significant $(P=0 \cdot 011)$ in the less wealthy districts, but not in the wealthy districts. Only girls in less wealthy districts demonstrated a statistically significant decrease in the prevalence of underweight during the three years $(P<0 \cdot 001)$. There was no clear gender difference in the

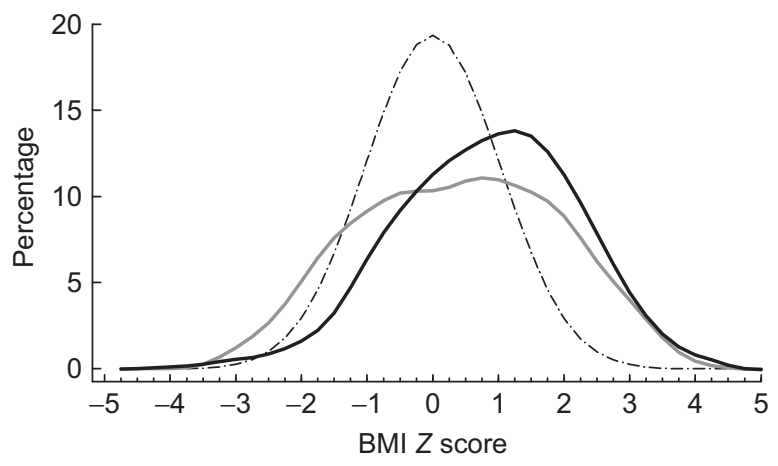

Fig. 2 Plot (Lowes curves) of BMI-for-age Z-score distributions for children aged 4 to 5 years from wealthy districts of Ho Chi Minh City, Vietnam, according to the 2002 (-) and 2005 surveys (-) and comparison with reference BMI curve (-.-) based on the Centers for Disease Control and Prevention 2000 Growth Reference ${ }^{(11)}$

changes in underweight prevalence for children in wealthy districts and the whole urban area. The combined prevalence of overweight and obesity for both genders in 2005 was nearly double that of 2002 (36.8\% and $21.4 \%$, respectively) and this difference was statistically significant $(P<0 \cdot 001)$. The increase in the prevalence of overweight and obesity over time was statistically significant in children of both genders $(P<0 \cdot 001)$. However, the difference was greater for boys than for girls. By 2005 the combined prevalence of overweight and obesity in boys had increased by $80 \%$ compared with $2002(40 \cdot 8 \%$ and $22 \cdot 6 \%$ respectively, $P<0.001$ ), while for girls in 2005 it had increased by $60 \%$ compared with $2002(32 \cdot 8 \%$ and $20 \cdot 4 \%$ respectively, $P<0 \cdot 001)$. The combined prevalence of overweight and obesity increased slightly in wealthy districts $(30 \cdot 1 \%$ in $2002 v .38 .5 \%$ in $2005, P=0.067$ ) but a statistically significant increase occurred for children from less wealthy districts $(16.9 \%$ in 2002 v. 35.9\% in 2005, $P<0 \cdot 001)$. 


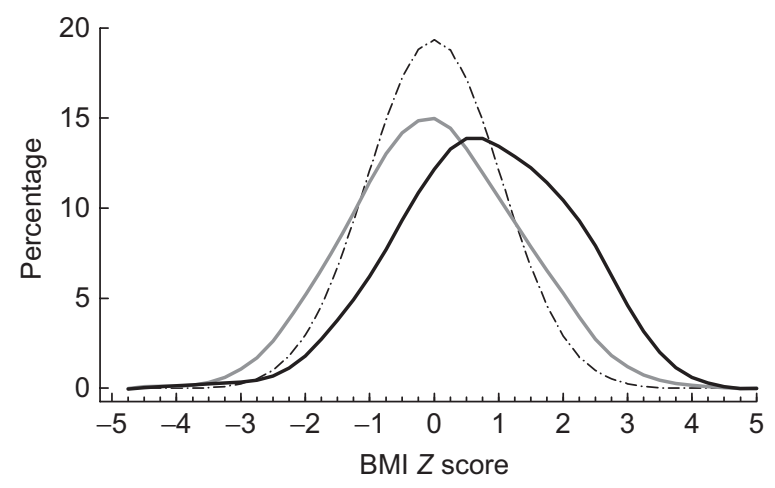

Fig. 3 Plot (Lowes curves) of BMI-for-age Z-score distributions for children aged 4 to 5 years from less wealthy districts of $\mathrm{Ho}$ Chi Minh City, Vietnam, according to the $2002(-)$ and 2005 surveys $(-)$ and comparison with reference BMI curve (---) based on the Centers for Disease Control and Prevention 2000 Growth Reference ${ }^{(11)}$

There was a gender difference in the change in obesity prevalence over time in less wealthy districts, with the percentage of boys classified as obese in 2005 being three times that observed in $2002(22.5 \% v .6 .9 \%, P<0.001)$.

Gender-specific logistic regression models used to assess the trends from 2002 to 2005 showed significant increases in the prevalence of overweight and obesity, and of obesity alone, in both genders after adjustment for age, pre-school location, parental overweight and parental education level (Table 4). The odds of becoming overweight/obese or obese over time were similar for both genders, with the odds of becoming overweight/obese and obese for boys of $2 \cdot 61(95 \%$ CI $1 \cdot 73,3 \cdot 96)$ and $2 \cdot 42(95 \%$ CI $1.43,4.09)$ respectively, and for girls of 1.80 (95\% CI $1 \cdot 19,2 \cdot 70)$ and $2 \cdot 45(95 \%$ CI $1 \cdot 22,4 \cdot 92)$ respectively.

\section{Discussion}

The present findings evidence a rapid increase in the prevalence of overweight and/or obesity, along with a substantial decrease in the prevalence of underweight, in children aged 4 to 5 years from 2002 to 2005 in urban areas of HCMC. The rate of increase in the prevalence of overweight and obesity, as well as changes in weight, height and BMI, were greater in children from less wealthy districts than in children from wealthy districts. These rapid changes in overweight and obesity prevalence were seen in comparable, representative samples of pre-school children in HCMC in both surveys. Thus, the importance of overweight and obesity in children of pre-school age in urban areas of HCMC is characterized not only by its magnitude ${ }^{(6)}$ but also by a rapidly increasing trend in prevalence over the 3 -year period from 2002 to 2005.

Similar trends have been observed in overweight and obesity prevalence in young child populations in other

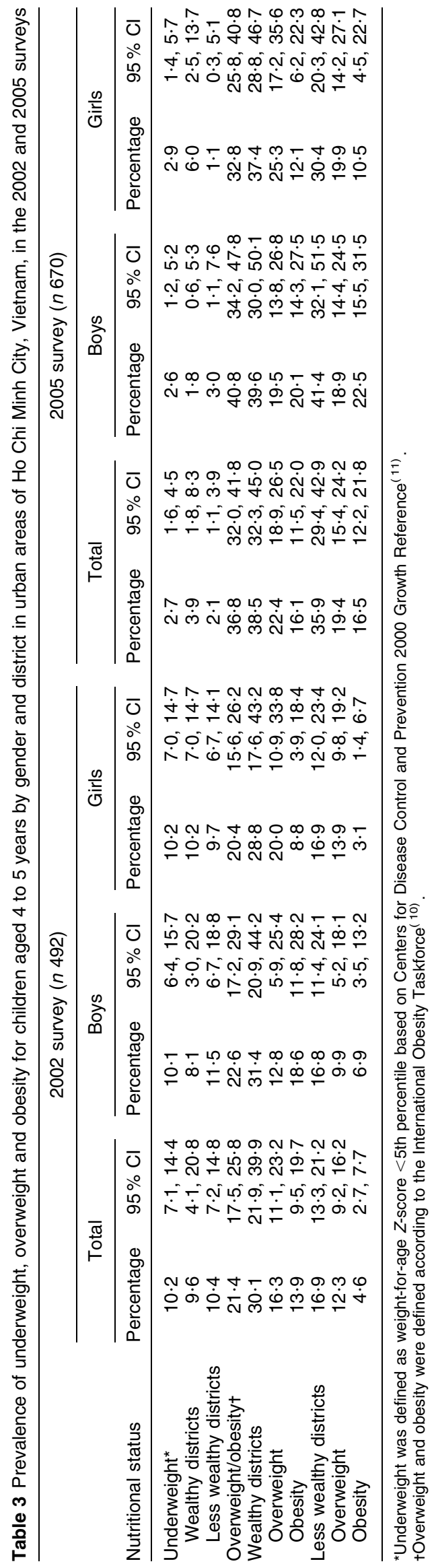


Table 4 Gender-specific logistic regression models of overweight and/or obesity over time adjusted for age, district, and parental overweight and education levels: children aged 4 to 5 years from urban areas of Ho Chi Minh City, Vietnam

\begin{tabular}{|c|c|c|c|c|c|c|c|c|}
\hline \multirow[b]{3}{*}{ Characteristic } & \multicolumn{4}{|c|}{ Overweight/obesity* } & \multicolumn{4}{|c|}{ Obesity* $^{*}$} \\
\hline & \multicolumn{2}{|c|}{ Boys } & \multicolumn{2}{|c|}{ Girls } & \multicolumn{2}{|c|}{ Boys } & \multicolumn{2}{|c|}{ Girls } \\
\hline & ORt & $95 \% \mathrm{Cl}$ & ORt & $95 \% \mathrm{Cl}$ & ORt & $95 \% \mathrm{Cl}$ & ORt & $95 \% \mathrm{Cl}$ \\
\hline $\begin{array}{l}\text { Age (months) } \\
\text { Year of survey }\end{array}$ & $1 \cdot 03$ & $1 \cdot 00,1 \cdot 06$ & $1 \cdot 02$ & $0 \cdot 98,1 \cdot 07$ & $1 \cdot 03$ & $0.97,1.09$ & $1 \cdot 05$ & $0 \cdot 97,1 \cdot 14$ \\
\hline 2002 & 1.00 & $-\S$ & 1.00 & - & 1.00 & - & $1 \cdot 00$ & - \\
\hline 2005 & $2 \cdot 61$ & $1 \cdot 73,3.96$ & $1 \cdot 80$ & $1 \cdot 19,2 \cdot 70$ & $2 \cdot 42$ & $1.43,4.09$ & $2 \cdot 45$ & $1 \cdot 22,4 \cdot 92$ \\
\hline \multicolumn{9}{|l|}{ District } \\
\hline Wealthy & 1.00 & - & 1.00 & - & 1.00 & - & $1 \cdot 00$ & - \\
\hline Less wealthy & 0.97 & $0 \cdot 66,1 \cdot 42$ & $0 \cdot 76$ & $0 \cdot 51,1 \cdot 13$ & $1 \cdot 01$ & $0 \cdot 63,1 \cdot 62$ & $0 \cdot 77$ & $0 \cdot 41,1 \cdot 42$ \\
\hline \multicolumn{9}{|l|}{ Parental overweightł } \\
\hline No parent overweight & 1.00 & - & $1 \cdot 00$ & - & $1 \cdot 00$ & - & $1 \cdot 00$ & \\
\hline One parent overweight & $1 \cdot 49$ & $0 \cdot 99,2 \cdot 24$ & $1 \cdot 83$ & $1 \cdot 21,2 \cdot 77$ & $2 \cdot 01$ & $1 \cdot 21,3 \cdot 33$ & $2 \cdot 91$ & $1 \cdot 39,6 \cdot 10$ \\
\hline Both parents overweight & $2 \cdot 59$ & $1 \cdot 37,4 \cdot 89$ & $4 \cdot 33$ & $2 \cdot 31,8 \cdot 09$ & $2 \cdot 49$ & $1 \cdot 20,5 \cdot 20$ & $5 \cdot 72$ & $2 \cdot 35,13 \cdot 95$ \\
\hline \multicolumn{9}{|l|}{ Parental education level } \\
\hline Primary school & $1 \cdot 00$ & - & $1 \cdot 00$ & - & $1 \cdot 00$ & - & $1 \cdot 00$ & - \\
\hline Secondary school & $1 \cdot 19$ & $0.40,3.53$ & $0 \cdot 74$ & $0 \cdot 27,2 \cdot 07$ & 0.64 & $0 \cdot 16,2 \cdot 54$ & $0 \cdot 77$ & $0 \cdot 15,4.05$ \\
\hline High school & $2 \cdot 09$ & $0 \cdot 73,5 \cdot 97$ & $1 \cdot 82$ & $0 \cdot 70,4 \cdot 72$ & $1 \cdot 69$ & $0.47,6.08$ & $1 \cdot 35$ & $0 \cdot 29,6 \cdot 29$ \\
\hline University & $2 \cdot 76$ & $0.95,8.05$ & $3 \cdot 06$ & $1 \cdot 16,8.06$ & $2 \cdot 15$ & $0.58,7.90$ & $1 \cdot 43$ & $0 \cdot 30,6 \cdot 85$ \\
\hline
\end{tabular}

*Overweight and obesity were defined according to the International Obesity Taskforce ${ }^{(10)}$.

tOR ratios and $95 \% \mathrm{Cl}$ calculated from logistic regression analysis.

$\neq$ Overweight in parents defined ${ }^{(12)}$ as $B M I \geq 23 \mathrm{~kg} / \mathrm{m}^{2}$.

$\S 95 \% \mathrm{Cl}$ not calculated (reference category).

developing countries during the past decade. Data from the China Health and Nutrition Survey collected from 1989 to 1997 have shown a dramatic increase in overweight and obesity among children aged 2 to 6 years in urban areas. That study, using the IOTF classification for overweight and obesity, reported that the prevalence of overweight increased from $14 \cdot 6 \%$ to $28 \cdot 6 \%$, and that of obesity increased from $1.5 \%$ to $12.6 \%$ over the period of study ${ }^{(14)}$. In Brazil, trends from 1975 to 1996 revealed a strong continuous decrease in the prevalence of stunting and wasting, and a doubling in the prevalence of overweight (defined as weight-for-height index $>+2$ sD based on 1978 WHO reference population) among pre-school children from higher income groups $(3.3 \%$ to $6.9 \%$ respectively) ${ }^{(15)}$. In a report of trends in overweight and obesity among children in Latin American countries, a similar phenomenon was documented among children in grade 1 in Chile, with the prevalence of overweight (weight-for-height index $>+2$ SD based on 1978 WHO reference population) increasing 2.9 times for boys and $2 \cdot 2$ times for girls over the thirteen years from 1987 to $2000^{(16)}$. Compared with other studies reporting trends in overweight and obesity in urban pre-school children, it appears that the $57 \%$ increase per year in the prevalence of overweight and obesity in pre-school children in HCMC was greater than that reported in China $(27 \%)^{(14)}$, Brazil $(17 \%)^{(15)}$ and Chile $(12 \%)^{(16)}$.

In the present study, increases in overweight and obesity were greater for boys than for girls, and especially the prevalence of obesity in boys which nearly doubled over the 3-year period (Table 3). More rapid increases in weight compared with height were observed in boys than in girls, leading to the gender differences observed in BMI over time. These findings are similar to those reported for adolescents from urban areas of HCMC from 2002 to 2004, where the prevalence of overweight and obesity in boys increased by $113 \%$ but in girls by only $39 \%{ }^{(5)}$. In contrast, several publications on the prevalence and trends in overweight and obesity among pre-school children in developed countries have shown an opposite trend by gender, with greater increases in overweight and obesity reported for girls than for boys ${ }^{(17-19)}$. These gender differences between Vietnam and Western countries may be explained by Vietnamese culture where boys are preferred over girls and often receive more of the family's resources. However, the role of male gender preference needs further examination in future studies of overweight and obesity in pre-school children in Vietnam.

Although the economic status of the participant households was not considered in these analyses due to the lack of information on household wealth in the 2002 survey, the wealth status of the district in which the school was located was classified. The greatest changes in BMI status and prevalence of overweight and obesity were observed in children from schools in less wealthy districts, which made the greatest contribution to the overall changes in BMI status and overweight and obesity prevalence in children from HCMC over the 3-year period. The high prevalence of overweight and obesity in the young child population in wealthy districts was shown in the 2002 and the 2005 data; however, there are no preceding data available to indicate when this epidemic began. Although the prevalence of overweight and obesity in pre-school children from less wealthy urban 
districts commenced from a lower level compared with that observed in wealthy urban districts, the greater rate of increase in the former resulted in similar prevalences by 2005 for children from both types of district. This implies that there have been substantial changes in the environment and lifestyle of families from less wealthy urban areas in recent years and that the socio-economic differences between these groups of urban districts are narrowing. It is necessary to understand what alterations in the environment led to changes in dietary and physical activity behaviour in these urban populations. Data are needed to assess and monitor the shift over time in the diets and physical activity of pre-school children.

The present study also found a substantial decline in underweight and wasting in this population. There was a more marked improvement in the prevalence of underweight and wasting in less wealthy compared with wealthy urban areas. Thus, underweight, a major health problem in pre-school children in HCMC in the 1980s, appears to be under control but is being replaced with an epidemic of overweight and obesity. This phenomenon has also been reported in countries that are considered to be experiencing the final stage of a 'nutrition transition' ${ }^{,(15,16,20)}$. However, the 'nutrition transition' in urban HCMC appears to have been much faster than that observed in other countries.

One limitation of the present study is the different information collected in the 2005 compared with the 2002 survey. Household socio-economic status, which is considered an important factor related to changes in overweight and obesity over time, could not be examined in our analyses because it was collected only in 2005. In addition, data on diet, physical activity patterns and the environment were not available in the 2002 survey. For these reasons, the factors associated with the time trends in overweight and obesity among this young child population could not be fully evaluated.

Since the study was conducted in pre-schools, selection bias is another limitation. Although the rate of pre-school attendance reported for children aged 4 to 5 years in 2005 was greater than $80 \%$, the remaining children in this age group who did not attend pre-school were not available for recruitment to our study. Generalization of our study findings should therefore be limited to children enrolled in pre-schools in urban HCMC.

In summary, the present study found a rapid rate of increase in the prevalence of overweight and obesity as measured by BMI in children aged 4 to 5 years in urban areas, and especially the less wealthy districts, of HCMC over a 3-year period. The urban areas of HCMC are now facing an increasing prevalence of overweight and obesity in both pre-school and older children. Since overweight and obesity in adolescents may be well established by the pre-adolescent period $^{(21)}$, in the near future the number of overweight adolescents may increase in HCMC if no attempt is made to prevent obesity at an early age.
Further investigation of the factors associated with change in BMI status in this young child population, which is particularly susceptible to obesity, is underway in a cohort study of risk factors for overweight and obesity in children of pre-school age in the urban areas of HCMC. The short-term and long-term health consequences of childhood obesity, as well as the associated health costs, indicate it is time to control and reverse the rapid upward trend in overweight and obesity in young children in HCMC and in other urban areas of Vietnam.

\section{Acknowledgements}

Conflicts of Interest: There are no potential conflicts of interest for any of the authors in relationship to this research or publication.

Sources of funding: This research was supported by the Wellcome Trust Research Training Fellowship (073153/Z/03/Z).

Author contributions: All authors have made significant contributions to the study and the manuscript and all authors are in agreement with the content of the manuscript.

Acknowledgements: We are grateful to the subjects who participated in this study. We gratefully acknowledge the assistance of the staff of the Nutrition Centre of HCMC and the pre-schools collaborators in HCMC.

\section{References}

1. Popkin BM (2002) An overview on the nutrition transition and its health implications: the Bellagio meeting. Public Health Nutr 5, 93-103.

2. Popkin BM (2002) What is unique about the experience in lower- and middle-income less-industrialised countries compared with the very-high income industrialised countries? Public Health Nutr 5, 205-214.

3. Ulla U, Pietinen P \& Puska P (2002) Dietary Transition in Developing Countries: Challenges for Chronic Disease Prevention. Geneva: WHO; available at http://whqlibdoc. who.int/publications/9241590416.pdf

4. Ho Chi Minh City Statistical Office (2003) Economic Growth of Ho Chi Minh City from 1995-2003. Ho Chi Minh City: Statistical Office.

5. Hong KT, Dibley MJ, Sibbritt DW, Binh NTP, Trang HDN \& Hanh TMT (2007) Overweight and obesity are rapidly emerging among adolescents in Ho Chi Minh City, Vietnam, 2002-2004. Int J Pediatr Obes 2, 194-201.

6. Dieu TTH, Dibley MJ, Sibbritt DW \& Hanh TMT (2007) Prevalence of overweight and obesity in preschool children and associated socio-demographic factors in Ho Chi Minh City, Vietnam. Int J Pediatr Obes 2, 40-50.

7. Canning PM, Courage ML \& Frizzell LM (2004) Overweight and obesity in preschool children in Newfoundland and Labrador. CMAJ 171, 240-242.

8. Ogden CL, Carroll MD, Curtin LR, McDowell MA, Tabak CJ \& Flegal KM (2006) Prevalence of overweight and obesity in the United States, 1999-2004. JAMA 295, 1549-1555.

9. Lohman TG, Roche AF \& Martorell R (1991) Anthropometric Standardization Reference Manual. Champaign, IL: Human Kinetics Publishers, Inc. 
10. Cole TJ, Bellizzi MC, Flegal KM \& Dietz WH (2000) Establishing a standard definition for child overweight and obesity worldwide: international survey. BMJ $\mathbf{3 2 0}$, 1240-1243.

11. Kuczmarkski RJ, Ogden CL \& Grummer-Strawn LM (2000) CDC Growth Charts: United States. Advance Data from Vital and Health Statistics no. 314. Hyattsville, MD: National Center for Health Statistics.

12. WHO Expert Consultation (2004) Appropriate bodymass index for Asian populations and its implications for policy and intervention strategies. Lancet 363 157-163.

13. Chambers J, Cleveland W \& Kleiner BT (1983) Graphical Methods for Data Analysis. Boston, MA: Duxbury Press.

14. Luo J \& Hu FB (2002) Time trends of obesity in pre-school children in China from 1989 to 1997. Int J Obes Relat Metab Disord 26, 553-558.

15. Monteiro CA, Conde WL \& Popkin BM (2002) Is obesity replacing or adding to undernutrition? Evidence from different social classes in Brazil. Public Health Nutr 5, 105-112.
16. Abala C, Vio F \& Kain J (2002) Nutrition transition in Chile: determinants and consequences. Public Health Nutr 5, 123-128.

17. Booth ML, Wake M, Armstrong T, Chey T, Hesketh $\mathrm{K}$ \& Mathur S (2001) The epidemiology of overweight and obesity among Australian children and adolescents, 1995-97. Aust N Z J Public Health 25, 162-169.

18. Ogden CL, Flegal KM, Carroll MD \& Johnson CL (2002) Prevalence and trends in overweight among US children and adolescents, 1999-2000. JAMA 288, 1728-1732.

19. Stamatakis E, Primatesta P, Chinn S, Rona R \& Falascheti E (2005) Overweight and obesity trends from 1974 to 2003 in English children: what is the role of socioeconomic factors? Arch Dis Child 90, 999-1004.

20. Kain J, Uauy R, Lera L, Taibo L \& Albala C (2005) Trends in height and BMI of 6-year-old children during the nutrition transition in Chile. Obes Res 13, 2178-2186.

21. Wardle J, Brodersen NH, Cole TJ, Jarvis MJ \& David RB (2006) Development of adiposity in adolescence: five year longitudinal study of an ethnically and socioeconomically diverse sample of young people in Britain. BMJ 332, 1130-1135. 